\title{
Autonomy, rationality and the wish to die
}

\author{
David M Clarke Monash University, Melbourne, Australia
}

\begin{abstract}
Although suicide has traditionally carried a negative sanction in Western societies, this is now being challenged, and while there remains substantial public concern surrounding youth and elder suicide, there is a paradoxical push to relax the prohibition under certain circumstances. Central to the arguments behind this are the principles of respect for autonomy and the importance of rationality. It is argued here that the concepts of rationality and autonomy, while valuable, are not strong enough to substantiate a categorical "right to suicide" and that the concepts of "understandability" and "respect" are more useful and able to provide the foundation for responding to a person expressing a wish to die. Roman suicide, sometimes held as an example of "rational suicide", illustrates the effects of culture, tradition and values on the attitudes to, and the practice of, suicide.
\end{abstract}

(Fournal of Medical Ethics 1999;25:457-462)

Keywords: Suicide; euthanasia

\section{Introduction}

Although suicide has always occurred, and over the centuries been a topic of interest for philosophers and others, in Western societies it has generally carried a negative sanction. Historically, this sanction has been religious, viewing suicide as a rejection of God's gift of life, and civil, where it was considered a failure to accept one's obligation to the state. More recently the social sanction has been institutionalised within medicine and psychiatry, and the suicidal person has been seen as mentally disturbed, a danger to himor herself, and an appropriate object of "care". About 20 in 100,000 males and 10 in 100,000 females die by suicide each year in the United States and other Western countries, and this rate is increasing. ${ }^{1-3}$ Of particular community concern are the higher than average rates in the elderly, ${ }^{4}$ and the increasing rate in young people. ${ }^{56}$

In the midst of this, however, is a seemingly paradoxical push to relax the moral prohibition on suicide, and to see suicides occurring in the face of adversity as "rational". This is particularly discussed in the context of euthanasia, physical illness and aging. The arguments come mainly in two forms; one emphasising the respect for individual autonomy, and the other the rational assessment of utility. Suicide as practised and written about by the Greek and Roman philosophers has been held up as an example of "rational suicide". This paper offers an analysis of these ideas in relation to the clinical and ethical aspects of suicide.

\section{The psychiatric view of suicide}

As described above, a very influential perspective of suicide in contemporary Western society is that provided by the concept of mental illness, defined broadly as a disturbance of the mind affecting thinking, mood, motivation and behaviour. Exact figures vary depending on how the presence of "mental illness" is determined, but studies generally indicate that most people who commit suicide have a disturbance of mental functioning. ${ }^{3-12}$ The most common diagnoses given are depression, personality disorder and alcohol dependence or abuse, and these often are present in combination. Phenomena commonly observed in suicidal patients are feelings of hopelessness, helplessness, ambivalence, hostility and loss of control, together with various cognitive distortions. ${ }^{13-16}$ The latter include a pessimistic view of the future, a limited consideration of possible options and impaired problem-solving ability. A further common cooccurrence is the presence of disrupted social relations. The decision to end one's life is usually taken in the context of exhausted individual, family and social network resources. ${ }^{17}$ This pattern of hopelessness, pessimism, a reduced ability to consider possible solutions, and perceived reduced social support is seen in both the young and the old. ${ }^{18}{ }^{19}$ Furthermore, people who proceed to suicide have usually had suicidal thoughts for some time. ${ }^{20}$

The importance of these observations does not lie in concluding that psychiatric illness "causes" suicide, but in noting that suicide rarely occurs in the absence of some persistent disturbance of mental functioning. Surprisingly perhaps, this is counter to public perception which often views suicide as an acute response to a life stress. ${ }^{21}$ Studies also show that only a small fraction of people who commit suicide have a terminal physical illness, although this group becomes more significant in the older age group. In a study of 
suicides over the age of 65 years, it was found that $14 \%$ had a terminal illness. ${ }^{22}$ Most patients with terminal illness do not wish an early death, and of those who do express the wish to die, almost all are found to have a depressive illness affecting judgment and decision making. ${ }^{23}$ The tragedy for the elderly is that when depressed and physically ill, the suicidal ideation is rarely identified or appropriately treated. ${ }^{44}$

Hence, we may conclude that suicide and the desire to die usually occur in the presence of altered mental states - that is, mental states that impair a person's ability to think rationally and to consider options fully. Nevertheless, there are times when people express the wish to die in the absence of depression or other state which might impair mental function, and the concept of "rational" suicide needs further consideration.

\section{Rational suicide}

To claim that any action, suicide in this case, is rational is to claim that there are good reasons for it - "that it is sensible, appropriate, in keeping with one's fundamental interests, and perhaps even admirable". ${ }^{25}$ It is to say that the action is taken after informed deliberation and not impetuously or directed too much by emotion. Motto defines a rational decision as having two characteristics: being realistic and having minimal ambivalence. ${ }^{26}$ The first criterion addresses the importance of gaining full knowledge of the options and consequences, the second the potential problem of transient desires being inconsistent with a person's more longstanding and fundamental values.

The first task is, therefore, to weigh up the risks and benefits, the utility if you like, of each option. This requires mental competency, itself not a simple matter to be sure about. ${ }^{27}{ }^{28}$ However, leaving that aside, this task involves gaining all possible facts and "imagining" all possible consequences. In the situation of writing advance directives, the hypothetical determination of "what if ..." has been shown to be difficult. ${ }^{29}$ In the consideration of life or death this would seem to be impossible. How can a person consider rationally the options "to be or not to be"? The phrase "I would be better off dead" is nonsensical in that there is no known sense of "being" after death. Even for people who hold the view that there is life after death, it is essentially of an unknown quality and a matter of faith rather than rational thought. If the state of death is considered to be a "nothingness", then even though life might be experienced as intolerable, no rational consideration of alternatives can be made. There are some, however, who wish to argue that death is knowable, and as Mayo puts it, "fully known. If it is annihilation, what else could one want to know about it"? 勡 Despite the attractive simplicity of this idea, remains difficult to conceive how one can, eithe cognitively or experientially, know "nothingness" Although one may imagine that death will be lik dreamless sleep or being under an anaesthetic, it an assumption or at best a guess. Nobody knows

It can, however, be argued that the question i suicide (if not always, sometimes) is not "to be o not to be", but "whether to die now or later" When considered in this way, the nature of existence or non-existence after death is still important in a rational assessment of the relative quality oft existence. Technically, the comparison cannot b8 made because of the presence of the unknown.

If we were to focus on another question, that is the "good" that is to be gained for oneself by suios cide, let us say freedom from pain or sufferingt such things can only be "good" when considered in the context of a human life. They are "good? when attained in life, but have no meaning outside of it. Indeed, the irony in suicide is that in order to overcome some adversity of life, life itself i obliterated.

The above discussion may sound a bit like split $\stackrel{\mathbb{}}{=}$ ting hairs, but is important when one considerres the decision at stake. It indicates that the decis 80 whether or not to commit suicide is usually made outside the realm of logical thought. That is notre say that it is irrational, though there are times when it patently is. Rather it is arational. (Perhaps the truly altruistic suicide is an exception, wher: there is another life for which the "good" can be considered.) In most situations, the consideratio to end one's life because of persistent physical o폴 mental pain cannot be made on rational ground? It is therefore highly sensitive to cognitive and affective dispositions - to despair, pessimism an cognitive distortions posited earlier. One commits suicide because one "no longer wants to relate t⿳亠口冋. this particular existence". ${ }^{31}$ In other words, it is matter of feelings, emotions and intuitions as much as cognitions.

This is an important issue because there is trend to speak less of the "morality" of suicide with its presumed overtones of religious judgmeno talism, and to speak more of the "rationality" of suicide as if rationality replaces morality in decides ing whether or when suicide is right or wrongs good or bad, and that it is objectively or reliabl determined. I am arguing here that it is neithey objectively determined, nor indicative of goodness or rightness. When the stakes are high, as in theo irreversible decision to commit suicide, the requirement for "rationality" needs to be high Not only must the act be logically derived fror the beliefs and values taken as premises, but the 
premises must be strongly supported. With respect to suicide, and perhaps with most major life decisions, these conditions cannot be met. In any case, the components of "rationality" - reason and premise - are culturally determined and so one would have to ask: "which rationality"? 32 Although suicide may be understandable in any particular circumstance, it is not technically rational. Furthermore, if something is understandable (or rational in the looser sense of the word), that does not mean it is for the best, all things considered, and in that sense moral. There may be more than one understandable (or "rational") view. Hence the need for deliberation. On the other hand, if something is not understandable (and seemingly irrational) to us, that does not mean it might not be understandable or seemingly rational to someone else. Understandability occurs only as we are able to identify and empathise with another person's situation and his or her feelings and values. It is therefore affected by our own situation, feelings and values. Wood ${ }^{33}$ points out that suicides frequently have both an instrumental and an expressive component. Frequently suicide arises out of, and expresses, a person's feelings of anger, meaninglessness, rejection or desire for revenge. What may not seem understandable or rational instrumentally, may, in fact, be quite understandable when the expressive nature is revealed. However, the ability to understand a person's wish to die still does not mean that suicide is for the best.

The point of these remarks is to illustrate that to come to a conclusion that an act of, or decision regarding, suicide is reasonable is not straightforward. The requirements for "rationality" cannot be formally met. "Understandability" is all that can be hoped for and that does not automatically direct us to the best decision, particularly in the light of the cognitive and affective distortions usually present. Such judgments in the end involve not only intellectual considerations, but a synthesis of the affective, empathic, intuitive, cognitive and interpersonal. The rejection of an absolute claim to rationality with respect to suicide, however, does not diminish the imperative to respect a person's autonomy, to whatever extent that itself is not impaired.

\section{Autonomy}

The term "autonomy" has its origins in reference to the self-rule or self-governance of the Greek city-states. This original meaning was then applied to individuals, and given moral status, by Kant. ${ }^{34}$ In common usage, it implies "being one's own person or being able to act according to one's beliefs or desires without interference". ${ }^{35}$ It thus requires the capacity to think rationally and to make a reasoned decision consistent with one's values, and the ability to think and act freely, without undue influence from others. Autonomy can be frustrated either by external forces (loss of liberty) or by one's own capacities (agency). The respect for autonomy means acknowledging and honouring a person's right to hold views, to make choices and to take actions based on his or her personal values and beliefs. This idea was expressed by Kant as a respect for persons; to violate a person's autonomy is to treat that person as a "means" rather than as an "end-in-themselves".

In its extreme form autonomy is presented as an individual right - in the present context, the "right to die". ${ }^{36}$ This is usually stated as being a function of one's freedom to choose (a liberty-right), provided that one's choice does not harm or violate the rights of another person. Battin, however, goes further and argues that the right to commit suicide is so strongly related to human dignity that it is a "fundamental" human right, not to be overridden by utilitarian concerns. ${ }^{37}$ Respect for an individual's view is also incorporated into utilitarianism under the concept of "interests" and "preferences", ${ }^{38}{ }^{39}$ although because utilitarianism considers the views of all "stakeholders", in the end it may clash with respect for individual autonomy.

Few people would not agree that respecting persons' autonomy is important. However, we need to understand what it is we are respecting. We are respecting persons' rights to exercise their ability to make independent decisions governing their life. An autonomous act will be made without coercion, on the basis of reason and consideration, and consistent with personal values or moral code. In an ideal model of autonomy, such personal values would also be autonomously or independently derived. This last requirement is clearly not possible. People develop and mature over many years in the midst of a variety of social institutions in which they are heavily influenced by parents, peers, culture and experience. As a result of identifications and dis-identifications they develop their own moral structure ${ }^{40}$ which includes a range of values, some of which may conflict. By the time people are adults, they will have values that they are able to express and affirm, as in a code, and other less well articulated values that will be held only as "intuitions". In addition, as a result of experience, a person will have developed a number of psychological and social needs which themselves may contradict deeply held values. The result is psychic conflict and ambivalence. Most people who commit or attempt suicide express ambivalence about their 
decision. ${ }^{20}$ Whether a person does or does not commit suicide is influenced by the thoughts, impulses and desires most prominent at the time. Such desires and impulses come out of his current predicament, interpreted in the context of his emotional needs and fears, social environment and overarching values and beliefs. In the light of this ambivalence in values and thought, and the impossibility of autonomy in the acquisition of principles and values, our concept of autonomy in the sense of independence of thought and action is considerably weakened. In the situation of a life crisis, or mental or physical illness, it is readily apparent that autonomy is even further impaired. Returning, therefore, to the notion of "respect for autonomy", we need also to be cognisant and respectful of the ways in which individual autonomy is limited in any situation. When a person expresses a wish to die, ambivalence is present. Actually, he would rather live, if he could only find a better solution. Demoralisation and a restricted view of options limit autonomy.

\section{Roman suicide}

Although it is not known how much suicide was practised in ancient Greece and Rome, it was certainly written about in the literature and practised by some. However, it is Stoicism that is credited with making suicide not just acceptable, but esteemed. ${ }^{41}$ One of the classic cases was that of Seneca, who in AD 65 was accused of involvement in a conspiracy to overthrow Nero. After being given the death sentence, Seneca, together with his wife and in the company of friends, cut his veins, then discussed philosophy and gave dictation to his secretaries, before finally drinking poison in a rather dramatic re-enactment of the death of Socrates. This apparently became the model for others. Roman suicides have been described as being theatrical and social events, marked with calm and philosophical overtones. ${ }^{42}$

Stoicism developed in a period of significant social demoralisation following the collapse of the Greek city-states and the Alexandrian empire. It built on the Cynic idea of separation of oneself from worldly matters and emphasised personal indifference to things around. This was a state of mind, whereby, through the mental indifference attained, adverse events would exert no power. The indifferent person was free. This was linked with a belief in predestination - that there was a divinely arranged course of events which a person was powerless to alter. A person became free when he accepted what was ordained and gave up his own desires and wishes. Unlike the Cynics, who lived simply, the Stoics retained the Epicurean preference for pleasure and material success. They believed renunciation of such was unnecessary a® long as they remained indifferent to them! Philos? ophy itself, at least for the philosophers, was con sidered to be a way of cultivating a mind that made one indifferent.

The Stoics did not fear death but, in philosophical way, attempted to practise the samo indifference towards it as to life. They wer intrigued by the idea of dying nobly and contem plated the deaths of their mentors. "Dying wella3 became as important as "living well". It has been suggested that one explanation for this emphasis lay in their restricted access to the traditionat opportunities for acquiring glory through militar or civic fame. ${ }^{43}$ Consequently, although nof condoning it generally, the Stoics did considejo suicide acceptable in some circumstances namely: in service to others (altruism); to avoig being forced to commit some evil; impoverishment; chronic physical illness, and mental infirmity. ${ }^{44}$ It also became a privileged form $\vec{f}$ capital punishment for the upper class, and following the glorified example of Socrates there developed a tradition of suicide. The Stoio attitude to suicide is summed up in the words of Seneca:

"The best thing which eternal law ever ordained was that it allowed to us one entrance into life, many exits. Must I await the cruelty either of disease or of man, when I can depart through the midst of torture, and shake off my troubles? Th is the one reason why we cannot complain of life it keeps no one against his will." ${ }^{45}$

It is difficult for us to interpret or understand Roman suicide because of the cultural distance between us and them, and because of the possibility of literary distortion in the accounts. There are apparent contradictions in the stance of the Stoics that are difficult to explain. First, is the belief in divine control of nature, alongside the insistence to take control over dying. Second, if their emphasis on developing an indifference te life's adversities whilst being willing to give up lifo because of sickness or poverty. Third, the ideal of indifference seems betrayed by their accumulation of wealth - Seneca himself had become verm wealthy, with extensive property and investments. ${ }^{46}$ While the Stoics were able t $\Theta$ discuss death and suicide in an apparently calm and reasoned way, the rather dramatic descrip tions of fearless philosophising in front of an audf? ence, the clear role-modelling that occurred and the contradictions in thought and practice betra profound ambivalences.

The Stoics are put forward as an example of rational, autonomous suicide - suicide which is 
reasonably considered with little emotion, and without fear. What seems paramount in the example of the Romans is their desire to be in control of their death and to face it nobly. This can be understood in the context of their previous privileged status and their frustrated feelings of entitlement and power. However, rather than being a rational suicide, it seems more to be a "rationalisation" of suicide that attempted to dull the pain or shame of life with a glorification of mental superiority and control over life and death. When there is little substantial dignity, death provides the final opportunity for its expression. The denial of an emotional context and expression, and the contradiction in their philosophy and practice, would seem to make Roman suicide a poor example of a healthy approach to life's adversities.

The Roman example also indicates to us the influence that social context and shared values have on people's attitude to suicide. There are contemporary examples of this phenomenon. In Hungary, the exceptionally high rates of suicide found in the south-east regions have been understood as part of a traditional acceptance of self-destruction in times of trouble. ${ }^{47}$ Conversely, the New Zealand Maori men and women have had substantially lower rates of suicide than the Pakeha (New Zealanders of European origin), and this has been attributed to the security and esteem gained from active involvement in the traditional Maori culture. ${ }^{48}$ This, and other evidence, ${ }^{4950}$ supports the idea put forward by Durkheim that suicide is very much related to sociocultural factors; particularly the level of integration in family, religious, political and economic life.

\section{Conclusion}

Discussions about the moral status of suicide are being fuelled by the more specific debate concerning euthanasia - that is, in the presence of pain or suffering or other irremedial circumstance, should people be allowed intentionally to end their lives and to receive professional help to do so. The arguments for this usually come as a plea for the respect for individual autonomy, and by way of conceptualising a "rational" suicide - the latter argument stating that, although life is generally to be affirmed, there are times or situations where it is rational to do otherwise.

The assertion of this paper is that the concepts of both autonomy and rationality alone are inadequate arguments for euthanasia or suicide because neither is present in such an ideal or pure form as to allow such a categorical defence. Rather than being rational, the strongly affective and evaluative aspects of the decision making need to be acknowledged. Consideration of personal and interpersonal aspects and values cannot be done in a purely unemotional manner, and this is the deficiency of Roman suicide as an ideal. In place of rationality, the concept of "understandability" is more meaningful and useful, though it is acknowledged that it may not appear to carry the same moral force. Similarly, where autonomy cannot be recognised, at least without considerable weakening of the concept, the Kantian concepts of dignity and respect for persons still remain.

In summary, while it is accepted that there are important principles carried behind the banners of autonomy and rationality, neither exist as ideal and categorical phenomena. They therefore cannot be used as blanket justifications for the permission of suicide. To consider the meaning of an expressed wish to die or a request to be allowed to die, the principles of respect for autonomy and rationality need to be taken into account, together with an evaluation of their degree of limitation. It is important to ask why a request is being made, to examine for cognitive distortions and impairments of coping, to try to understand the expressive nature of the wish, and to consider these in the person's situational and developmental context. Even in the elderly and the sick there are developmental stages to be passed and crises that can be met in ways that give meaning and affirm life. ${ }^{51}$ Many elderly sick experience loneliness and desertion, and an expressed wish to die in these circumstances should not be presumed to be autonomous. Rather, depression, pessimism, fear and social isolation can all be met and addressed in authentic ways that gives respect to the person. ${ }^{52}$

One of the great advantages of the notions of autonomy and rationality is their force in moral argument. Terms such as "understandability" or "respect for the person" may seem, at first, not as helpful because they seem to carry less moral weight and direct us less obviously to a particular conclusion. This is not a reason for abandoning them in favour of apparently more useful but less valid concepts. An exaggerated emphasis on autonomy can lead to an avoidance of listening to, and understanding, the patient. Where rationality is overemphasised, the expressive and emotional meaning of a wish to die will be overlooked. A clinical approach to a person expressing a wish to die must seek to understand all these aspects and develop a coherent understanding of the person, including his or her thoughts, desires, values and relationships. 


\section{Acknowledgments}

This paper was written during a period of study undertaken in the Bioethics Research Centre at the University of Otago. I am grateful to Professor Grant Gillett and Professor Bela Blasszauer for helpful comments.

David M Clarke MBBS, MPM, PhD, FRACGP, FRANZCP, is Associate Professor in the Department of Psychological Medicine, Monash University, Melbourne, Australia. Correspondence to: $\mathrm{Dr}$ DM Clarke, Department of Psychological Medicine, Monash Medical Centre, 246 Clayton Road, Clayton, Vic 3168, AUSTRALIA. e-mail: david.clarke@ med.monash.edu.au

\section{References}

1 Clark DC. "Rational" suicide and people with terminal conditions or disabilities. In: Battin MP, Mayo DJ, eds. Suicide: the philosophical issues. New York: St Martin's Press, 1980,147-66.

2 Dyck RJ, Newman SC, Thompson AH. Suicide trends in Canada, 1956-1981. Acta Psychiatrica Scandinavica 1988;77: 411-19.

3 Chynoweth R, Tonge JI, Armstrong J. Suicide in Brisbane: a retrospective psychosocial study. Australian and New Zealand Fournal of Psychiatry 1980;14:37-45.

4 Duckworth G, McBride H. Suicide of the elderly: a tragedy of neglect. Canadian fournal of Psychiatry 1996;41:217-22.

5 Kosky RJ, Goldney RD. Youth suicide: a public health problem? Australian and New Zealand Fournal of Psychiatry 1994;28:186-7.

6 Prosser J, McArdle P. The changing mental health of children and adolescents: evidence for a deterioration? Psychological Medicine 1996;26:715-25.

7 Henriksson MM, Aro HM, Marttunen MJ, Heikkinen ME Isometsä ET, Kuoppasalmi KI, et al. Mental disorders and comorbidity in suicide. American foumal of Psychiatry 1993; 150:935-40

8 Lesage AD, Boyer R, Grunberg F, Vanier C, Morisette R, Ménard-Buteau C, ct al. Suicide and mental disorders: a casecontrol study of young men. American fournal of Psychiatry 1994;151:1063-8.

9 Barraclough B, Bunch J, Nelson B, Sainsbury P. A hundred cases of suicide: clinical aspects. British fournal of Psychiatry 1974; 125:355-73.

10 Beskow J. Suicide and mental disorder in Swedish men. Acta Psychiatrica Scandinavica 1979;277(suppl 1):121-38.

11 Dorpat TL, Ripley HS. A study of suicide in the Seattle area Comprehensive Psychiatry 1960;1:349-59.

12 Rich CL, Young D, Fowler RC. San Diego suicide study: I Young vs old subjects. Archives of General Psvchiatry 1986;43 577-82.

13 Mendonca JD, Holden RR. Are all suicidal ideas closely linked to hopelessness? Acta Psychiatrica Scandinavica 1996;93:24651

14 O'Donnell I, Farmer R Catalán J. Explaining suicide: the views of survivors of serious suicide attempts. British fournal of Psychiatry 1996;168:780-6.

15 Horesh N, Rolnick T, Iancu I, Dannon P, Lepkifker E, Apter A, et al. Coping styles and suicide risk. Acta Psychiatrica Scandinavica 1996;93:489-93

16 Isometsä ET, Henriksson MM, Heikkinen ME, Aro HM, Marttunen MJ, Kuoppasalmi KI, et al. Suicide among subjects with personality disorders. American fournal of Psychiatry 1996; 153:667-73.

17 Richman J. Family therapy for suicidal people. New York: Springer, 1986

18 Leenaars AA. Suicide notes of the older adult. Suicide and LifeThreatening Behavior 1992;22:62-9.
19 Hawton K. Youth suicide: trends indicate increasing hopeles ness in young males. Crisis 1994;15:159-60.

20 Litman RE. Suicidology: a look backward and ahead. Suicit and Life-Threatening Behavior 1996;26:1-7.

21 Sawyer D, Sobal J. Public attitudes toward suicide: demo̊ graphic and ideological correlates. Public Opinion Quarterl 1987;51:92-101.

22 See reference $1: 152$.

23 Chochinov HM, Wilson KG, Enns M, Mowchun N, Lander Levitt M, et al. Desire for death in the terminally ill. Americ Fournal of Psychiatry 1995;152:1185-91.

24 Isometsä ET, Aro HM, Henriksson MM, Heikkinen ME, Lö क्क nqvist JK. Suicide and major depression in different treatme settings. Fournal of Clinical Psychiatry 1994;55:523-7.

25 Mayo DJ. The concept of rational suicide. Fournal of Medicify and Philosophy 1986;11:143-155 (page 144).

26 Motto JA. The right to suicide: a psvchiatrist's view: See refeence $1: 212-19$

27 Kopelman LM. On the evaluative nature of competency an capacity judgements. International foumal of Law and Psvchis try 1990;13:309-29.

28 Brock DW, Wartman SA. When competent patients make irra tional choices. New England fournal of Medicine 1990;32\$ $1595-9$.

29 Savulescu J. Rational desires and the limitation of lif sustaining treatment. Bioethics 1994;8:191-222.

30 Mavo DJ. Contemporary philosophical literature on suicide: review. Suicide and Lifo-Threatening Behavior 1983;13:313-h (page 322)

31 Clements CD. The ethics of not-being: individual options $f$ suicide. See reference 1:104-14

32 MacIntyre A. Whose justice? Which rationality? Notre Dameg University of Notre Dame Press, 1988.

33 Wood D. Suicide as instrument and expression. See referen $1: 151-60$

34 Dworkin G. The nature of autonomy. In: Dworkin G. T theory and practice of autonomy' Cambridge: Cambridge Unives sity Press, 1988:3-33

35 Agich GJ. Key concepts: autonomy. Philosophy, Psychiatr Psychology 1994;1:267-9 (page 267)

36 Anonymous. The right to die. British Medical fo 1994;308:66.

37 Battin MP. Suicide: a fundamental human right? See refe $1: 267-85$.

38 Kuhse H. Interests. Fournal of Medical Ethics 1985;11:146-9.

39 Hare RM. Utilitarianism and deontological principles. In: G Ion R, Lloyd A, eds. Principles of health care ethics. Chichest John Wiley \& Sons, 1994:149-57.

40 Kohlberg L, Hersh RH. Moral development: a review of the theory. Theory into Practice 1977;16:53-9.

41 Griffin M. Roman suicide. In: Fulford KWM, Gillett GR, So kice JM, eds. Medicine and moral reasoning. Cambridge Cambridge University Press, 1994:106-30.

42 See reference $41: 108$

43 See reference 41:122

44 Carrick P. The problem of euthanasia. In: Carrick P. Medic ethics in antiquity: philosophical perspectioes on abortion and euth $\$$ nasia. Dordrecht: D Reidel, 1985:127-150.

45 See reference 44:145.

46 Cohen SG. Lucius Annaeus Seneca (4 BC-79 AD): Romai orator, author, and statesman. Allergy Proceedings 1995;16:210 11.

47 Farkasinszky T, Onody S, Bacskai M, Szilard J. Data on th sociological causes of suicide in Csongrad County. Nepeges zsegugy 1979;60:291-6.

48 Skegg K, Cox B, Broughton J. Suicide among New Zealaro Maori: is history repeating itself? Acta Psychiatrica Scandinavi 195;92:453-9.

49 Trovato F. A Durkheimian analysis of youth suicide: Canadఖ 1971 and 1981. Suicide and Life-Threatening Behavior 1992;22; 413-27.

50 Gould MS, Fisher P, Parides M, Flory M, Shaffer D. Psychos cial risk factors of child and adolescent completed suicide Archives of General Psychiatry 1996;53:1155-62.

51 Butler RN. Successful aging and the role of the life revieu Fournal of the American Geriatrics Society 1974;22:529-35.

52 Richman J. A rational approach to rational suicide. Suicide a Life-Threatening Behavior 1992;22:130-41. 